\title{
Tyrphostin AG 126
}

National Cancer Institute

\section{Source}

National Cancer Institute. Tyrphostin AG 126. NCI Thesaurus. Code C1713.

A member of the tyrphostin family of tyrosine kinase inhibitors, that actively blocks lipopolysaccharide-induced production of tumor necrosis factor-a and nitric oxide in macrophages. $(\mathrm{NCl})$ 